\title{
Allogeneic Stem Cell Transplantation in Relapsing Multipl Myeloma after Autologous Stem Cell Transplantation: Single Center Experience
}

\section{Otolog Kök Hücre Nakli Sonrası Nüks Multipl Myelom Hastalarında Allojenik Kök Hücre Transplantasyonu: Tek Merkez Deneyimi}

\author{
Mehmet Bakırtaş, Bahar Uncu Ulu, Semih Başcı, Tuğçe Nur Yiğenoğlu, Jale Yıldız, Alparslan Merdin, DERYA \\ ŞAHİN, Tahir Darçın, DİCLE İSKENDER, Merih Kızıl Çakar, MEHMET SINAN DAL, Fevzi Altuntas \\ Hematoloji ve Kemik İliği Nakil Merkezi, Ankara Dr. Abdurrahman Yurtaslan Ankara Onkoloji Eğitim ve \\ Araştırma Hastanesi \\ Dergiye Ulaşma Tarihi: 14.12.2019 Dergiye Kabul Tarihi:01.04.2020 Doi: 10.5505/aot.2020.75769
}

\section{ÖZET}

GİRIŞ ve AMAÇ: Yeni ajanlar döneminde tedavi edilen multipl myelom (MM) hastalarında, bu ajanlara hiç maruz kalmamış hastalarla karşılaştırıldığında nüksten itibaren genel sağkalımda (OS) iyileşme gözlenmiştir. Bununla birlikte, yeni ajanlar kullanılsa dahi bazı hastalarda zamanla direnç gelişir ve tekrarlayan nüksler yaşanmaya devam eder. Allojenik kök hücre nakli (AKHN), yüksek riskli sitogenetik özellik taşıyan ve otolog kök hücre nakli (OKHN) sonrası erken dönemde nüks olan fit hastalar için potansiyel küratif seçenek oluşturur. YÖNTEM ve GEREÇLER: Aralık 2009-Aralık 2017 yılları arasında indüksiyon tedavisinde en az bir yeni ajan alan, OKHN sonrası nüks eden ve AKHN yapılan 9 hastanın verileri geriye dönük olarak analiz edildi. BULGULAR: Tüm hastalarda AKHN sırasında medyan yaş 42 (aralık 25-56 yaş), AKHN sonrası medyan takip süresi 31.5 ay idi. Tüm hastalarda nakil sonrası OS 27 ay ve progresyonsuz sağkalım (PFS) 15 ay bulundu. Fludarabin-busulfan verilen hastalarda medyan PFS 18 ay, OS 69 ay; siklofosfamid-total vücut 1şınlaması (TBI) verilen hastalarda medyan PFS 4 ay, OS 6 ay saptandı. Transplant ilişkili mortalite (TRM) \%11 olarak saptandı. TARTIŞMA ve SONUÇ: Yüksek risk özellikleri taşıyan MM hastalarında kemoterapiye refrakter ya da OKHN sonrası relaps durumlarda AKHN tedavi seçeneği olarak düşünülebilir. Yeni tanı veya standart riskli relaps refrakter MM hastalarında standart yaklaşım olarak düşünülmemelidir.

Anahtar Kelimeler: Multiple Myeloma, allojenik kök hücre nakli, relaps.

\begin{abstract}
INTRODUCTION: In the era of new agents, overall survival (OS) of multiple myeloma (MM) patients have improved compared to patients who had never received these agents. However, some patients develop resistance to new agents and relapse over time. Allogeneic stem cell transplantation (allo-SCT) is a potential curative option for fit patients with high-risk cytogenetic features and in patients who relapse early after autologous stem cell transplantation (ASCT).

METHODS: The data of 9 MM patients who received at least one novel agent during induction treatment and underwent allo-SCT after relapse following ASCT between December 2009 and December 2017 were analyzed retrospectively.

RESULTS: The median age at the time of allo-SCT was 42 years (range 25-56 years) in all patients, and the median follow-up period was 31.5 months. Median OS after allo-SCT was 27 months and median progression free survival (PFS) was 15 months in all patients. Median PFS was 18 months and OS was 69 months in patients who received fludarabine-busulfan and median PFS was 4 months, OS was 6 months in patients who received cyclophosphamide-total body irradiation (TBI). Transplant-related mortality (TRM) was $11 \%$. DISCUSSION AND CONCLUSION: Allo-SCT may be considered as a treatment option after relapse following ASCT in MM patients with high risk characteristics. Allo-SCT should not be considered in initial treatment or in relapse refractory MM patients with standard risk.

Keywords: Multiple Myeloma, Allogeneic stem cell transplantation, relapse
\end{abstract}

\section{GíRiș}

Nüks eden Multipl Miyelom (MM) hastaları için tedavi seçeneklerine son 10 yılda çok sayıda yeni ajanlar katılmışır. Lenalidomide, pomalidomide, bortezomib, karfilzomib, daratumumab, elotuzumab, ixazomib ve panobinostat gibi ajanlar nüks refrakter $\mathrm{MM}$ tedavisinde kullanılmaya başlanmıştır. Yeni ajanlarla tedavi edilen hastalar, bu ajanlara hiç 
maruz kalmayan hastalarla karşılaştırıldığında nüksten itibaren genel sağkalımda iyileşme gözlenmiş̧tir(OS) [1]. Bununla birlikte, yeni ajanlarla dahi bazı hastalarda zamanla direnç gelişir ve tekrarlayan nüksler yaşanmaya devam eder; bu nedenle uzun süreli hastalık kontrolü sağlanamaz. Allojenik kök hücre nakli (AKHN), yüksek riskli sitogenetik özellik taşıyan ve otolog kök hücre nakli (OKHN) sonrası erken dönemde nüks olan fit hastalar için potansiyel küratif seçenek oluşturur [2,3]. Bununla birlikte, destekleyici bakımdaki iyileşmelere rağmen, myeloablatif hazırlama rejimleri ile yapılan AKHN; organ toksisiteleri, graft-versus-host hastalığ1 (GVHH) ve enfeksiyonlara bağlı olarak \% 2044 oranında non-relaps mortaliteye (NRM) sahiptir [4,5]. Hazırlık rejimlerinin toksisitesini azaltmak ve donör lenfoid hücrelerin immünolojik etkisini (yani graft-versus-tümör etkisini) korumak için 1990'ların sonlarında azaltılmış yoğunluklu hazırlama rejimleri (RIC) uygulanmaya başlanmıştır [6]. Günümüzde, RIC ardından yapılan AKHN'nin en iyi sonuçları, yeni tanı konmuş $\mathrm{MM}$ hastalarında OKHN ile tümör yükünün azaltılmasının ardından yapılan nakillerde bildirilmiştir. Tek başına OKHN ile OKHN ardından RIC ile yapılan AKHN karşılaştıran randomize çalışmaların bazıları AKHN yapılan hastalarda daha üstün PFS ve OS göstermiştir $[7,8]$. AKHN, MM tedavisinde halen standart yaklaşım değildir, transplant ilişkili mortalite oranlarının yüksek olması nedenli kullanımı sinırlıdır ve sadece yüksek risk özellikleri taşıyan dirençli ve nüks $\mathrm{MM}$ hastaları için deneysel tedavi durumundadır. Literatürdeki MM hastalarında AKHN ile ilgili çalışmalarda hastaların çoğu konvansiyonel kemoterapilerle tedavi edilmiştir. Yeni ajanlarla tedavi edilen MM hastalarında AKHN ile ilgili çalışma sayısı azdır. Yeni ajanlar döneminde ve gelişen destek tedavisi 1şı̆̆ında yeni çalışmalara ihtiyaç vardır. $\mathrm{Bu}$ nedenle çalışmamızda merkezimizde yeni ajanlar döneminde AKHN yapılan ve indüksiyon tedavisinde en az bir yeni ajan alan MM hastalarının verilerinin incelenmesi hedeflendi.

\section{HASTALAR VE YÖNTEMLER}

Aralık 2009-Aralık 2017 y1lları arasında indüksiyon tedavisinde en az bir yeni ajan alan, OKHN sonrası nüks eden ve AKHN yapılan 9 hastanın verileri geriye dönük olarak analiz edildi.

Hastalık yanıtı; klinik muayene, kan ve 24 saatlik idrar tetkikleri, kemik iliği biyopsi analizi, pozitron emisyon tomografi (PET-BT) ve bilgisayarlı tomografi (BT) ile değerlendirildi. Hastalarda karyotip analizi ve floresan in situ hibridizasyon (FISH) ile $\mathrm{t}(14$; 16), $\mathrm{t}(11 ; 14), \mathrm{t}(4 ; 14)$, delesyon $17 \mathrm{p} 13$, delesyon $13 q 14$ çalışıldı. $t(4 ; 14), \quad t(14 ; 16)$ ve/veya del $17 \mathrm{p}$ varlığı yüksek riskli genetik olarak kabul edildi [9]. Yanıt, MM için uluslararası cevap kriterlerine göre değerlendirildi [10].

Altı hastada hazırlama rejimi olarak fludarabine $\left(30 \mathrm{mg} / \mathrm{m}^{2}\right.$, D-10 ve D-5 aras 1 toplam 6 gün), busulfan (2 ardışık gün boyunca 6 saate bir $0.8 \mathrm{mg} / \mathrm{kg}$; toplam $3.2 \mathrm{mg} / \mathrm{kg} / \mathrm{gün}$ ) ve tavşan ATG $(2.5 \mathrm{mg} / \mathrm{kg} / \mathrm{gün})$ kullanılırken 3 hastada hazırlama rejimi olarak siklofosfamid (D-6, D-5, D+3, D+4. günlerde $50 \mathrm{mg} / \mathrm{kg} /$ gün), total vücut 1şınlaması (TBI) (D-3, D-2, D-1. günlerde $2 \times 1$ Gray/gün; toplam 6 Gray) kullanıldı. GVHH profilaksisi, hastaların tümünde siklosporin ile yapıldı. Akut GVHH şiddeti, Uluslararası Kemik İliği Nakil Kayitları (IBMTR) derecelendirme sistemine göre derecelendirildi. Kronik GVHH, Ulusal Sağlık Enstitüsü (NIH) 2015 konsensüs kriterlerine göre derecelendirildi $[11,12]$.

Engraftman tanımı; nötrofil için ardışı 3 gün boyunca desteksiz mutlak nötrofil sayisinın $\left(\right.$ ANS) $>500 / \mathrm{mm}^{3}$ veya $1000 / \mathrm{mm}^{3}$ olduğu ilk gün, trombosit için ise $\operatorname{ard}$ şsı 3 gün boyunca desteksiz trombositlerin $>20000 / \mathrm{mm}^{3}$ olduğu veya $50000 / \mathrm{mm}^{3}$ olduğu ilk gün olarak tanımland. OS, AKHN tarihinden ölüm ya da hayatta olanlar için son gözleme kadar geçen süre olarak tanımlandı. PFS ise $\mathrm{AKHN}$ tarihinden nüks, progresyon, ölüm veya son gözleme kadar geçen süre olarak tanımlandı. Non relaps mortalite (NRM), MM ile ilişkili olmayan tüm nedenlerden dolayı ölüm olarak tanımlandi.

İstatistiksel Analiz için IBM SPSS Statistics (versiyon 21) paket program1 kullanıldı. Verileri özetlemek için tanımlayıcı istatistikler kullanıldı Değişkenlerin normal dağılıma uygunluğu görsel (histogram ve grafikler) ve analitik yöntemlerle (ShapiroWilk testi) incelendi. Kategorik veriler oran olarak, sayısal veriler medyan ve ortalama \pm standart sapma olarak belirtildi. PFS ve OS için Kaplan Meier sağkalım analizi ve 
sağkalımı etkileyen faktörleri incelemek için log-rank testleri kullanıldı. $P$ değerinin $\leq 0,05$ olduğu değerler istatistiksel olarak anlamlı kabul edildi.

\section{SONUÇLAR}

Merkezimizde OKHN sonrası nüks eden ve AKHN yapılan 9 hastanın altısı erkek, üçü kadındı. Tüm hastalarda AKHN sırasında medyan yaş 42 (aralık 25-56 yaş), erkek hastalarda medyan yaş 44 (aralık 25-56 yaş), kadın hastalarda medyan yaş 42 (aralık 31-51 yaş) idi. Hastaların demografik özellikleri, MM alt grupları ve tanı anındaki evreleri Tablo 1 'de verilmiştir. AKHN sonrası medyan takip süresi 31.5 ay idi (aralık 5-61 ay). İlk tanı ile AKHN arasındaki medyan süre 17 ay idi (aralık 9-56 ay). Hastaların üçüne tam yanıt (TR), bir tanesine çok iyi kısmi yanıt(VGPR), ikisine kısmi yanıt (PR), üçüne ise aktif hastalık ile AKHN yapıldı. Tüm hastalarda nakil sonrası OS 27 ay ve PFS 15 ay bulundu (Şekil 1). Hastaların hepsine tam uyumlu kardeş vericilerinden kök hücre kaynağı olarak periferik kan kullanılarak nakil yapıldı. Medyan engraftman süreleri nötrofil ve trombosit için sırasıyla 16 ve 13 gün olarak saptand. Hazırlık rejimi olarak Cy-TBI alanlarda medyan nötrofil ve trombosit engraftman süreleri sirasıyla 15 gün ve 13 gün iken; hazırlık rejimi olarak Flu-Bu-ATG alanlarda sirasıyla 16 gün ve 13 gün olarak saptand1. Nakil sonras1 median PFS ve OS hazırlık rejimi olarak Cy-TBI verilen grupta sirasıyla 4 ay ve 6 ay iken; hazırlık rejimi olarak Flu-Bu-ATG verilen grupta sirasıly 18 ay ve 69 aydi. Flu-Bu-ATG alan hastaların birisinde Grade 2 akut karaciğer GVHH, birisinde ise grade 2 akut cilt GVHH gelişirken kronik GVHH görülmedi. Cy-TBI alan hastaların hiçbirinde akut ya da kronik GVHH görülmedi. Tüm hastalardan sadece 1 tanesinde tanı anında FISH ile bak1lan 17p13 delesyonu vard1, diğer hastalarda ise karyotip incelemesinde anomali ya da FISH ile bakılan $\mathrm{t}$ $(14 ; 16), \mathrm{t}(11 ; 14), \mathrm{t}(4 ; 14)$, delesyon $17 \mathrm{p} 13$, delesyon 13q14'de pozitiflik saptanmadi. TRM \%11 olarak saptand.

Tablo 1: Hastaların Özellikleri

\begin{tabular}{|l|l|l|l|}
\hline $\begin{array}{c}\text { NAKİL } \\
\text { YAŞI }\end{array}$ & $\begin{array}{c}\text { CINSIYY } \\
\text { ET }\end{array}$ & $\begin{array}{l}\text { MM } \\
\text { SUBTIP }\end{array}$ & EVRE \\
\hline 38 & Erkek & $\begin{array}{l}\text { Kappa } \\
\text { Hafif }\end{array}$ & DS-2A \\
\hline
\end{tabular}

Adress.or correspondence: Uzm. Dr. Semih Başcı Dr.abdurrahman Yurtaslan Ankara Onkoloji Eğit. Ve Araş. Hastanesi

e-mail: semih1736@hotmail.com

Available at www.actaoncologicaturcica.com

Copyright $\mathbb{C}$ Ankara Onkoloji Hastanesi

\begin{tabular}{|l|l|l|l|}
\hline & & Zincir & \\
\hline 37 & Erkek & $\begin{array}{l}\text { IgA } \\
\text { Kappa }\end{array}$ & DS-3A \\
\hline 51 & Erkek & $\begin{array}{l}\text { IgG } \\
\text { Lambda }\end{array}$ & DS-3A \\
\hline 25 & Erkek & $\begin{array}{l}\text { Kappa } \\
\text { Hafif } \\
\text { Zincir }\end{array}$ & DS:3A \\
\hline 51 & Kadın & $\begin{array}{l}\text { IgG } \\
\text { Lambda }\end{array}$ & $\begin{array}{l}\text { DS-3A; } \\
\text { ISS:3 }\end{array}$ \\
\hline 42 & Kadın & $\begin{array}{l}\text { IgA } \\
\text { Kappa }\end{array}$ & $\begin{array}{l}\text { DS-3A; } \\
\text { ISS-2; R- } \\
\text { ISS-2 }\end{array}$ \\
\hline 31 & Kadın & $\begin{array}{l}\text { Lambda } \\
\text { Hafif } \\
\text { Zincir }\end{array}$ & $\begin{array}{l}\text { DS-3A; } \\
\text { ISS-1 }\end{array}$ \\
\hline 50 & Erkek & $\begin{array}{l}\text { IgG } \\
\text { Kappa }\end{array}$ & $\begin{array}{l}\text { DS-3A; } \\
\text { ISS-3 }\end{array}$ \\
\hline 56 & Erkek & $\begin{array}{l}\text { IgG } \\
\text { Kappa }\end{array}$ & $\begin{array}{l}\text { DS-3; } \\
\text { ISS-1; R- } \\
\text { ISS-2 }\end{array}$ \\
\hline
\end{tabular}

DS: Durie Salmon; ISS: Uluslararası Evreleme Sistem

\section{TARTIŞMA}

Özellikle OKHN sonrası nüks/refrakter olan MM hastalarında AKHN uzun yıllardır kullanılan bir tedavi seçeneği olmuştur [1315]. Ancak yüksek TRM ve GVHH oranları nedeniyle AKHN, MM tedavisinde yaygın kullanım alanı bulamamıştır. Çalışmalarda AKHN, OKHN'ne kıyasla daha yüksek moleküler yanıt, daha uzun süreli hastalık kontrolü ve daha yüksek TRM'ye rağmen graft versus myeloma etkisi ile ilişkili bulunmuştur. RIC ve non myeloablatif hazırlama rejimlerinin kullanılması, destek tedavilerindeki iyileşmelerle AKHN nüks refrakter $\mathrm{MM}$ hastalarında potansiyel küratif bir tedavi seçeneği olmuştur. Uluslararası Myeloma Çalışma Grubuna (IMWG) göre yüksek risk özellikleri gösteren yeni tanı MM hastalarinda konvansiyonel tedavilerle beklenen 4 yıllık OS \%33'tür [16]. Yüksek sitogenetik riske sahip MM hastaları ile standart risk sitogenetik özelliklere sahip hastaların AKHN sonrası benzer OS ve PFS'ye sahip olmaları AKHN'nin yüksek risk sitogenetik özelliklerin prognoz üzerine olan olumsuz etkisini kırdığını düşündürmektedir.

Kroger ve arkadaşlarının yaptığ prospektif çalışmada OKHN sonrası AKHN yapılan hastalarda del $(17 \mathrm{p}) / \mathrm{t}(4 ; 14)$ olan ve olmayanların sonuçları karşılaştırıldığında benzer remisyon oranı ve benzer OS, PFS 
süreleri saptanmıştır[17]. Bizim çalışmamızda sadece bir hasta yüksek riskli genetik özelliklere sahipti ve bu hasta TRM nedenli kaybedildi.

Yin ve arkadaşlarının yaptığ 1 analizde 100 günlük TRM \%12 saptanmıştır [18]. Bu oran bizim çalışmamızda bulunan 100 günlük TRM \%11 ile benzerdir. TRM'nin yüksek olmasının nedeni çalışmada yer alan hastaların daha önce çok sayıda kemoterapi dizesi almış olan ve daha önce OKHN olan dirençli hastalar olması olabilir.

Yin ve arkadaşlarının yaptığı analizde akut GVHH'nin daha kısa OS ve PFS süreleri ile ilişkili olduğu, hafif kronik GVHH'nin ise graft versus myeloma etkisi nedenli OS'1 uzatabildiği saptanmıştır [19, 20, 21]. Kroger ve arkadaşları ATG'nin akut GVHH riskini azalttığını [22] saptasa da, bizim çalışmamızda bu durumun aksine Flu-Bu-ATG hazırlama rejimi ile AKHN olan hastalarda GVHH görülürken, Cy-TBI alanlarda GVHH saptanmadı. Yin ve arkadaşlarının yaptığı çalışmada AKHN öncesi yanıt derinliği daha uzun süreli OS ve PFS için bağımsız bir prognostik faktör olarak bulunmuştur [18]. Bizim çalışmamızda AKHN öncesi tam yanıtı olanlarda daha uzun OS saptanırken PFS benzer bulundu. $\mathrm{Bu}$ da kurtarma tedavilerine rağmen kemosensitif yanıt alınamaması halinde bu hastalarda da aktif hastalik ile AKHN'nin tercih edilebileceğini düşündürmektedir.

Fabre ve arkadaşlarının yaptığ prospektif bir çalışmada 50 yaş üzeri hastalarda daha kısa OS ile ilişki bulunmuştur [23]. Bizim çalışmamızda 4 hasta 50 yaş ve üzeri idi ve bunlarda medyan OS 24 ay idi, 3 hasta ise 50 yaş altında idi ve bunlarda medyan OS 30 ay saptand.

Kroger ve arkadaşlarının [24] yaptığ çalışmada kadın donör kullanılması daha az relaps ve progresyon oranı ile ilişkili bulunurken, bizim çalışmamızda kadın ve erkek donörlerden yapılan nakillerde OS ve PFS fark1 saptanmadi.

\section{SONUC}

AKHN, yeni tan1 veya standart riskli relaps refrakter MM hastalarında standart tedavi yaklaşımı olarak düşünülmemelidir. Yüksek TRM oranları nedenli sadece yüksek risk sitogenetik özellikleri taşıyan MM hastalarında kemoterapiye ve yeni ajanların dahil olduğu tedavi seçeneklerine refrakter ya da nüks durumlarda AKHN tedavi seçeneği olarak düşünülmelidir.

\section{REFERANSLAR}

1. Kumar SK, Rajkumar SV, Dispenzieri A, et al. Improved survival in multiple myeloma and the impact of novel therapies. Blood. 2008;111:25162520.

2. Martinelli G, Terragna C, Zamagni E, et al. Molecular remission after allogeneic or autologous transplantation of hematopoietic cells for multiple myeloma. J Clin Oncol. 2000;18: 2273-2281.

3. Corradini $\mathrm{P}$, Cavo $\mathrm{M}$, Lokhorst $\mathrm{H}$, et al. for the Chronic Leukemia Working Party of the European Group for Blood and Marrow Transplantation. Molecular remission after myeloablative allogeneic stem cell transplantation predicts a better relapsefree survival in patients with multiple myeloma. Blood. 2003;102: 1927-1929.

4. Bjorkstrand BB, Ljungman $\mathrm{P}$, Svensson $\mathrm{H}$, et al. Allogeneic bone marrow transplantation versus autologous stem cell transplantation in multiple myeloma: a retrospective case-matched study from the European Group for Blood and Marrow Transplantation. Blood. 1996;88:4711-4718.

5. Gahrton G, Svensson H, Cavo M, et al. for the European Group for Blood and Marrow Transplantation. Progress in allogenic bone marrow and peripheral blood stem cell transplantation for multiple myeloma: a comparison between transplants performed 1983-93 and 1994-8 at European Group for Blood and Marrow Transplantation centres. $\mathrm{Br} \mathrm{J}$ Haematol. 2001;113:209-216.

6. Maloney DG, Molina AJ, Sahebi F, et al., Allografting with nonmyeloablative conditioning following cytoreductive autografts for the treatment of patients with multiple myeloma. Blood. 2003;102:3447-3454.

7. Bruno B, Rotta M, Patriarca F, et al. A comparison of allografting with autografting for newly diagnosed myeloma. N Engl J Med. 2007;356:1110-1120.

8. Gahrton $\mathrm{G}$, Bjorkstrand $\mathrm{B}$, Iacobelli $\mathrm{S}$, et al. on behalf of the Chronic Leukemia Working Party. Long-term follow-up of upfront tandem autologous-RIC (reduced intensity conditioning) allogeneic transplantation versus autologous transplantation (NMAM2000) in multiple myeloma. Bone Marrow Transplant. 2010;45:85a.

9. Nijhof I, Donk N, Zweegman S, Lokhorst H. Current and New Therapeutic Strategies for Relapsed and Refractory Multiple Myeloma: An Update. Drugs (2018) 78:19-37

10. Durie BG, Harousseau JL, Miguel JS, et al. for the International Myeloma Working Group. International uniform response criteria for multiple myeloma. Leukemia. 2006;20:1467-1473.

11. Rowlings PA, Przepiorka D, Klein JP, et al. IBMTR Severity Index for grading acute graft-

Adress.or correspondence: Uzm. Dr. Semih Başcı Dr.abdurrahman Yurtaslan Ankara Onkoloji Eğit. Ve Araş. Hastanesi

e-mail: semih1736@hotmail.com

Available at www.actaoncologicaturcica.com

Copyright $\subset$ Ankara Onkoloji Hastanesi 
versus-host disease: retrospective comparison with Glucksberg grade. Br J Haematol 1997; 97:855.

12. Filipovich AH, Weisdorf D, Pavletic S, Socie G, Wingard JR, Lee SJ, et al. National Institutes of Health consensus development project on criteria for clinical trials in chronic graft-versus-host disease: I. Diagnosis and staging working group report. Biol Blood Marrow Transpl. 2005;11(12):945-56.

13. Thomas ED, Lochte HL Jr, Lu WC, Ferrebee JW. Intravenous infusion of bone marrow in patients receiving radiation and chemotherapy. $\mathrm{N}$ Engl $\mathrm{J}$ Med. 1957;257(11):491-6.

14. Tricot $G$, Vesole DH, Jagannath S, Hilton J, Munshi N, Barlogie B. Graftversus-myeloma efect: proof of principle. Blood. 1996;87(3):1196-8.

15. Gahrton G, Tura S, Ljungman $P$, et al. Allogeneic bone marrow transplantation in multiple myeloma. European Group for Bone Marrow Transplantation. N Engl J Med. 1991;325(18):1267-73.

16. Avet-Loiseau $\mathrm{H}$, Durie $\mathrm{BG}$, Cavo $\mathrm{M}$, et al. Combining fuorescent in situ hybridization data with ISS staging improves risk assessment in myeloma: an International Myeloma Working Group collaborative project. Leukemia. 2013;27(3):711-7.

17. Kroger $N$, Badbaran $A$, Zabelina $T$, et al. Impact of high-risk cytogenetics and achievement of molecular remission on long-term freedom from disease after autologous-allogeneic tandem transplantation in patients with multiple myeloma. Biol Blood Marrow Transplant. 2013;19(3):398404

18. Yin X, Tang L, Fan F, Jiang Q, Sun C, Hu Y. Allogeneic stem-cell transplantation for multiple myeloma: a systematic review and meta-analysis from 2007 to 2017. Cancer Cell Int (2018) 18:62
19. Andrykowski MA, Bishop MM, Hahn EA, et al. Long-term health-related quality of life, growth, and spiritual wellbeing after hematopoietic stemcell transplantation. J Clin Oncol. 2005;23(3):599608.

20. Clavert A, Peric Z, Brissot E, Malard F, Guillaume T, Delaunay J, Dubruille V, Le Gouill S, Mahe B, Gastinne T, et al. Late complications and quality of life after reduced-intensity conditioning allogeneic stem cell transplantation. Biol Blood Marrow Transplant. 2017;23(1):140-6.

21. Garcia CM, Mumby $P B$, Thilges $S$, Stif PJ. Comparison of early quality of life outcomes in autologous and allogeneic transplant patients. Bone Marrow Transplant. 2012;47(12):1577-82.

22. Kroger N, Einsele H, Derigs G, Wandt H, Krull A, Zander A. Long-term follow-up of an intensifed myeloablative conditioning regimen with in vivo $\mathrm{T}$ cell depletion followed by allografting in patients with advanced multiple myeloma. Biol Blood Marrow Transplant. 2010;16(6):861-4

23. Fabre C, Koscielny S, Mohty M, et al. Younger donor's age and upfront tandem are two independent prognostic factors for survival in multiple myeloma patients treated by tandem autologous-allogeneic stem cell transplantation: a retrospective study from the Societe Francaise de Grefe de Moelle et de Therapie Cellulaire (SFGMTC). Haematologica. 2012;97(4):482-90

24. Kröger N, Perez-Simon JA, Myint H, et al. Relapse to prior autograft and chronic graft-versus-host disease are the strongest prognostic factors for outcome of melphalan/fludarabine-based dosereduced allogeneic stem cell transplantation in patients with multiple myeloma. Biol Blood Marrow Transplant. 2004; 10:698-708. 